Article

\title{
Cholecalciferol Additively Reduces Serum Parathyroid Hormone Levels in Severe Secondary Hyperparathyroidism Treated with Calcitriol and Cinacalcet among Hemodialysis Patients
}

Cai-Mei Zheng ${ }^{1,2,3}$, Chia-Chao Wu ${ }^{4}$, Chi-Feng Hung ${ }^{5,6}$, Min-Tser Liao ${ }^{7,8}$, Jia-Fwu Shyu ${ }^{9}$, Yung-Ho Hsu 1,2,3, Chien-Lin Lu 1,10, Yuan-Hung Wang 1,11, Jing-Quan Zheng 1,12, Tian-Jong Chang ${ }^{13,14}$, Yuh-Feng Lin ${ }^{1,2,3, *}$ and Kuo-Cheng Lu 1,10,*

1 Graduate Institute of Clinical Medicine, College of Medicine, Taipei Medical University, Taipei 11031, Taiwan; 11044@s.tmu.edu.tw (C.-M.Z.); yhhsu@s.tmu.edu.tw (Y.-H.H.); janlin0123@gmail.com (C.-L.L.); 12072@s.tmu.edu.tw (Y.-H.W.); jingquan235@gmail.com (J.-Q.Z.)

2 Division of Nephrology, Department of Internal Medicine, Shuang Ho Hospital, Taipei Medical University, New Taipei City 235, Taiwan

3 Department of Internal Medicine, School of Medicine, College of Medicine, Taipei Medical University, Taipei 11031, Taiwan

4 Division of Nephrology, Department of Internal Medicine, Tri-Service General Hospital, National Defense Medical Center, Taipei 114, Taiwan; wucc@ndmctsgh.edu.tw

5 School of Medicine, Fu-Jen Catholic University, New Taipei City 242, Taiwan; 054317@gmail.com

6 Graduate Institute of Biomedical and Pharmaceutical Science, Fu-Jen Catholic University,

New Taipei City 242, Taiwan

7 Department of Pediatrics, Taoyuan Armed Forces General Hospital, Taoyuan 325, Taiwan; liaoped804h@yahoo.com.tw

8 Division of Pediatrics, Department of Medicine, Tri-Service General Hospital, National Defense Medical Center, Taipei 114, Taiwan

9 Department of Biology and Anatomy, National Defense Medical Center, Taipei 114, Taiwan; shyujeff@mail.ndmctsgh.edu.tw

10 Division of Nephrology, Department of Medicine, Cardinal-Tien Hospital \& Fu-Jen Catholic University Hospital, School of Medicine, Fu-Jen Catholic University, New Taipei City 242, Taiwan

11 Department of Medical Research, Shuang Ho Hospital, Taipei Medical University, New Taipei City 235, Taiwan

12 Division of Critical Care, Department of Critical Care Medicine, Shuang Ho Hospital, Taipei Medical University, New Taipei City 235, Taiwan

13 Graduate Institute of Life Sciences, National Defense Medical Center, Taipei 114, Taiwan; 10247@s.tmu.edu.tw

14 Performance Appraisal Section, Secretary Office, Shuang Ho Hospital, Taipei Medical University, Taipei 235, Taiwan

* Correspondence: linyf@shh.org.tw (Y.-F.L.); kuochenglu@gmail.com (K.-C.L.)

Received: 18 January 2018; Accepted: 8 February 2018; Published: 10 February 2018

Abstract: We evaluated the improvement of intact parathyroid hormone (iPTH) levels and bone parameters by supplementing nutritional vitamin D (cholecalciferol) to combined calcimimetic (cinacalcet) and active vitamin D analog (calcitriol) among severe secondary hyperparathyroidism (SHPT) hemodialysis (HD) patients. A randomized, controlled open-label study was undertaken in $60 \mathrm{HD}$ patients with serum iPTH $>1000 \mathrm{pg} / \mathrm{mL}$ or persistently high iPTH $\geq 600 \mathrm{pg} / \mathrm{mL}$ even after $>3$ months of calcitriol ( $3 \mu \mathrm{g} /$ week). The study group received oral cholecalciferol (5000 IU/ day) and the control group received a placebo. All patients received fixed dose cinacalcet (30 mg/day, orally) and calcitriol. Calcitriol was reduced if iPTH $\leq 300 \mathrm{pg} / \mathrm{mL}$ and cinacalcet was withdrawn if serum iPTH was persistently low (iPTH $\leq 300 \mathrm{pg} / \mathrm{mL}$ ) for 4 weeks after the reduction of calcitriol. A significantly lower iPTH level was noted from the 20th week in the study group compared to the 
placebo group, and the target iPTH $\leq 300 \mathrm{pg} / \mathrm{mL}$ was achieved at the 24th week in the study group. Most patients achieved serum $25-(\mathrm{OH}) \mathrm{D}_{3} \geq 30 \mathrm{ng} / \mathrm{mL}$ in the study group. Nearly $40 \%$ of study patients gained $>10 \%$ improvement in femoral neck (FN) bone mineral density (BMD). We conclude that cholecalciferol additively reduced serum iPTH levels, improved $25-(\mathrm{OH}) \mathrm{D}_{3}$ levels and improved FN BMD when used together with cinacalcet/calcitriol in severe SHPT HD patients.

Keywords: cholecalciferol; hemodialysis; secondary hyperparathyroidism; cinacalcet; calcitriol

\section{Introduction}

Secondary hyperparathyroidism (SHPT) is a major complication among dialysis patients which can have renal osteodystrophy and cardiovascular consequences [1,2]. Dietary control, phosphate binders and active vitamin D analogs are used in earlier SHPT whereas calcimimetic agent, cinacalcet, is indicated in later stages of SHPT cases who have markedly elevated parathyroid hormone (PTH) levels or failed to respond earlier treatment. The doses of active vitamin D analogs are reduced or cinacalcet is added when the patients have progressively high calcium, phosphate and $\mathrm{Ca} \times \mathrm{P}$ products to prevent cardiovascular and soft-tissue calcification [3,4]. Many studies demonstrated that cinacalcet improves PTH control and achieves recommended serum calcium and phosphorus values when used in combination with active vitamin D analogs and phosphate binders [5-9]. In our previous study, we revealed additional PTH lowering and anti-inflammatory effects of nutritional vitamin D (cholecalciferol) supplementation to active vitamin D analogs in SHPT patients [10]. However, data regarding the addition of cholecalciferol supplementation to combined cinacalcet and active vitamin $\mathrm{D}$ analogs in severe SHPT patients is still lacking.

Circulating PTH levels were found to be inversely correlated with serum $25(\mathrm{OH}) \mathrm{D}_{3}$, a circulating vitamin D metabolite which indicated the vitamin $\mathrm{D}$ status $[11,12] .25(\mathrm{OH}) \mathrm{D}_{3}$ was an important substrate for the local generation of $1,25(\mathrm{OH})_{2} \mathrm{D}$ with the help of local $1 \alpha$-hydroxylase ( $1 \alpha$-OHase) activity $[13,14]$. Most end-stage renal disease (ESRD) patients had low serum $25(\mathrm{OH}) \mathrm{D}_{3}$ levels $[15,16]$. Segersten et al. [17] revealed $1 \alpha-\mathrm{OH}$ ase expression in parathyroid glands which presumably suppressed the PTH gland hyperplasia in an autocrine/paracrine manner. Previous research revealed coincident increased expression of $1 \alpha$-OHase (approximately increased in 10 folds) and reduced 24-hydroxylase in most SHPT glands [18] and highlighted the requirement of more $25(\mathrm{OH}) \mathrm{D}_{3}$ in these patients. CS Ritter et al. [19] proved that the local effect of $25(\mathrm{OH}) \mathrm{D}_{3}$ on PTH suppression possibly occurs through direct activation of the vitamin D receptor (VDR) in parathyroid glands. Furthermore, $25(\mathrm{OH}) \mathrm{D}_{3}$ played less role in systemic hypercalcemia and related complications. These findings explain the possible additive role of nutritional vitamin D (cholecalciferol) supplementation in SHPT patients.

Among two types of parathyroid cells (chief cells (CC) and oxyphil cells (OC)), OC markedly increased in chronic kidney disease (CKD) [20]. Lomonte $C$ et al. revealed calcitriol therapy significantly increases the OC content in parathyroid glands [21]. Cinacalcet acts through CaR in the CC of parathyroid glands and exerts antiproliferative and proapoptotic action [22,23]. Studies revealed that cinacalcet significantly increases the OC/CC ratio (approx. increase 3.42 times) [24] and increases the oxyphil area [25]. These OC excessively express $1 \alpha$ OHase enzyme and increase local calcitriol production [26], which further carries out autocrine/paracrine regulation of PTH synthesis and release. Thus, cinacalcet use further increases the requirement of substrate chocalciferol for $1 \alpha$ OHase to produce local calcitriol production in OC. Calcimimetics also up-regulate decreased parathyroid $\mathrm{CaR}$ and VDR in both in vitro and in vivo studies $[27,28]$ which further mediates parathyroid proliferation.

Therefore, we speculate that combining cinacalcet to calcitriol therapy increases the parathyroid OC/CC ratio, increases local $1 \alpha \mathrm{OHase}$ activity, and increases VDR expression which additively needs more $25(\mathrm{OH}) \mathrm{D}_{3}$ for local calcitriol synthesis. We hypothesize that the cholecalciferol supplementation in SHPT patients together with calcitriol and cinacalcet therapy increase local calcitriol production, 
which further suppresses intact parathyroid hormone (iPTH) secretion. We further describe the changes in bone turnover markers and bone densities with or without cholecalciferol supplementation in SHPT hemodialysis patients.

\section{Materials and Methods}

\subsection{Study Design}

The trial was designed as a randomized, controlled open-label study. A total of 80 patients were eligible and agreed to participate. Group matching with gender, age (within 5 years), and duration of hemodialysis (within 1 year) was conducted for every pair group and they were then randomly assigned to either treatment with cinacalcet, calcitriol and cholecalciferol (CCC, study group) or control group, treated with cinacalcet, calcitriol and placebo (CCP, control group). G*power was used to calculate the required sample size [29] and effects were detected in a two-sided test with a power of $(1-\beta)=80 \%$ at a significance level of 0.05 . Other calculation settings were as follows: (1) the randomization process was based on 1:1 proportion of this study; (2) the effect size was set as 0.8 . The required sample size for calculating was at least 25 subjects in the CCC group and 25 subjects in the CCP group.

\subsection{Patient Eligibility and Randomization}

Patients aged above 18 years treated with maintenance hemodialysis three times per week for at least 3 months before screening were eligible. Patients with severe SHPT (serum iPTH $>1000 \mathrm{pg} / \mathrm{mL}$ or persistantly high serum iPTH $\geq 600 \mathrm{pg} / \mathrm{mL}$ even after more than 3 months of calcitriol treatment) were enrolled. All patients needed to stop receiving an active vitamin D at least 30 days before entering the study. Patients using calcimimetic agents and/or native vitamin D analogs were excluded. The patients were excluded if they were pregnant, breastfeeding or of childbearing potential and not practicing birth control. Those with malignancies, severe malnutrition, and inflammatory or infectious disorders diagnosed for more than 3 months before the study were also excluded. Other exclusion criteria included surgical interventions and vascular diseases, including acute coronary syndrome, unstable angina, cerebrovascular accident, transient ischemic attack, deep vein thrombosis, pulmonary embolism, or congestive heart failure within 3 months of the study period. The patients were also excluded if they had a history of allergy to medications (Figure 1). Sixty hemodialysis (HD) patients fulfilled the criteria and were randomized into the CCC study group $(N=30)$ and CCP control group $(N=30)$. Patients were well matched by treatment allocation (Figure 1). Protocol and informed consent were approved by the authorities of the Institutional Review Board of Cardinal Tien Hospital and Taipei Medical University (CTH106A-2B01 and CTH-104-3-5-022). All the patients provided written consent before study enrollment. 


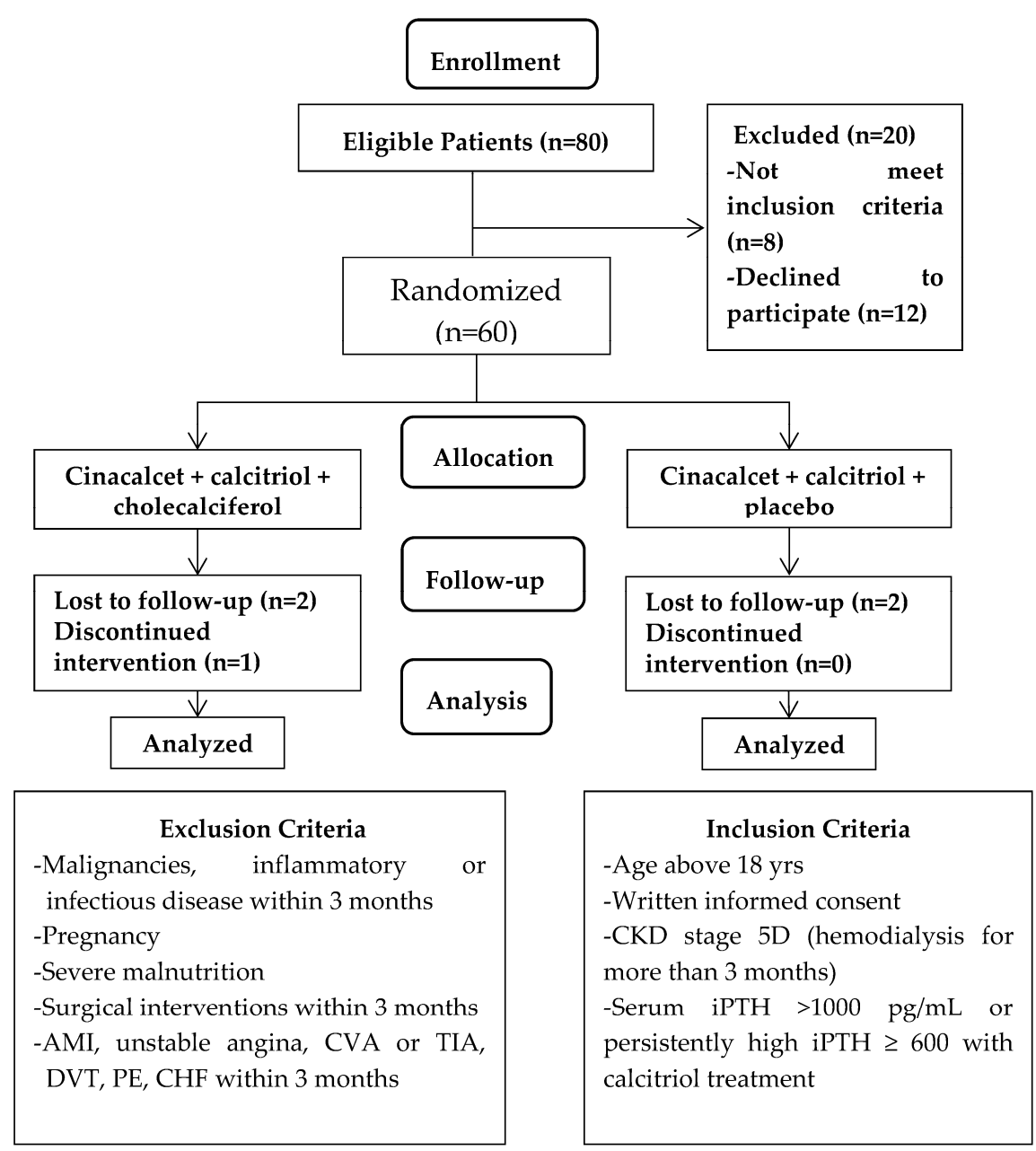

Primary Outcome Measures:

- Serum iPTH levels $\leq 300 \mathrm{pg} / \mathrm{mL}$

Secondary Outcome Measures:

- Serum 25-(OH)D3 $\geq 30 \mathrm{ng} / \mathrm{mL}$

- $10 \%$ improvement in femoral neck bone mineral density from baseline

AMI: acute myocardial infarction; CVA: cerebrovascular accident; TIA: transient ischemic attack; DVT: deep vein thrombosis; PE: pulmonary embolism; CHF: congestive heart failure; CKD stage 5D: chronic kidney disease stage 5 dialysis; iPTH: intact parathyroid hormone; 25-(OH)D3: 25-hydroxy vitamin $\mathrm{D}_{3}$

Figure 1. Study participants' flow chart.

\subsection{Treatment Intervention}

All patients were given oral cinacalcet ( $30 \mathrm{mg}$ /day) from the start of the study. Patients in the study group were given an oral form of cholecalciferol 5000 IU per day (Healthy Origens, Pittsburgh, PA 15241, USA); and cholecalciferol placebo (olive oil) was given in the control group. During the treatment, the calcitriol dose could be decreased when iPTH was $\leq 300 \mathrm{pg} / \mathrm{mL}$ and $\mathrm{Ca} \times \mathrm{P}$ was $>55 \mathrm{mg}^{2} / \mathrm{dl}^{2}$. The doses of Ca-based and other phosphate binders could be adjusted throughout the study. Ca-based phosphate binders could be increased when the serum Ca was $<8.4 \mathrm{mg} / \mathrm{dL}$ or the patient had symptoms of hypocalcemia. Cinacalcet was given in a fixed low dose (30 $\mathrm{mg}$ /day) during the whole study period, and was withdrawn if the serum iPTH was persistently low (iPTH $\leq 300 \mathrm{pg} / \mathrm{mL}$ ) for 4 weeks after the reduction of calcitriol or serum calcium $<8.4 \mathrm{mg} / \mathrm{dl}$ 
or the patient had symptoms of hypocalcemia. All patients used low dialysate Ca $2.5 \mathrm{mEq} / \mathrm{L}$ and adjusted according to serum Ca levels throughout the study. A baseline visit was performed just before the start of the study, and further study visits were performed at 4, 8, 12, 16, 20 and 24 weeks after the medication. Serum biochemical parameters and bone turnover markers were assessed at baseline and during follow-up. The femoral neck (FN) and lumbar spine (LS) bone mineral density (BMD) were determined by dual X-ray absorptiometry (DXA) before and at the end of the study period. Hospital records were obtained and examined by two practicing nephrologists.

\subsection{Serum Biochemical and Bone Metabolism Parameters}

Blood samples were collected and serum was separated within $1 \mathrm{~h}$ of collection and immediately frozen until analysis. Serum levels of iPTH, $25(\mathrm{OH}) \mathrm{D}_{3}$, phosphorus, calcium and other bone metabolism parameters were determined. Serum iPTH levels were measured in an immunoradiometric assay (Nichols Institute Diagnostics, San Juan Capistrano, CA, USA). Serum $25(\mathrm{OH}) \mathrm{D}_{3}$ was determined by enzyme-linked immunosorbent assay (ELISA) according to the manufacturer's instructions (Immundiagnostik AG, Bensheim, Germany). Serum bone specific alkaline phosphatase (BAP), a marker of bone formation was determined by ELISA (Quidel, Inc., San Diego, CA, USA); whereas tartrate-resistant acid phosphatase (TRACP)-5b, a marker of bone resorption was measured by ELISA (Quidel ${ }^{\circledR}$, Tecomedical Group, Sissach, Switzerland). The doses of calcitriol, cinacalcet and phosphate binders were recorded at each visit. Adverse events were collected from patients' reports and in response to non-directed questioning at each study visit.

\subsection{Objectives and Outcomes and Measures}

Our study used the Kidney Disease Outcomes Quality Initiative (K/DOQI) [30,31] targeted bone metabolism levels; serum Ca 8.4-9.5 mg/dL, P 3.5-5.5 mg/dL, iPTH 150-300 pg/mL. Interpretation of DXA scans using lumbar spine BMD was not precise in our patients since it might have been interfered with by aorta calcification and degenerative joint diseases. Thus, we used $10 \%$ improvement in femoral BMD instead of lumbar spine BMD as our outcome.

Primary Outcome: The primary outcome measure was serum iPTH $\leq 300 \mathrm{pg} / \mathrm{mL}$.

Secondary Outcome: The secondary outcome measures were serum $25-(\mathrm{OH}) \mathrm{D}_{3} \geq 30 \mathrm{ng} / \mathrm{mL}$ and $10 \%$ improvement in femoral neck BMD from baseline.

\subsection{Data Collection and Statistical Analysis}

The results were expressed as mean \pm standard deviation or median (interquartile range). Parametric or non-parametric tests were used for analysis; for paired data, the Student $t$ or Wilcoxon tests, respectively, and for between-group comparisons, the Student $t$, one-way ANOVA or Mann-Whitney U tests were used. Unilateral correlation analysis was performed using Pearson (r) or Spearman correlation (rs), as appropriate. All the tests were two-sided, and $p<0.05$ was considered statistically significant. Statistica (Version 11, Stat Soft, Inc., 2300 East 14th Street, Tulsa, OK 74104, USA) was used for calculations.

\section{Results}

\subsection{Patient Recruitment and Analysis Sets}

Table 1 shows the demographic characteristics of the study patients. All the patients were under HD with severe SHPT (serum iIPTH > $1000 \mathrm{pg} / \mathrm{mL}$ ) or persistently high SHPT (serum iIPTH $\geq 600 \mathrm{pg} / \mathrm{mL}$ ) even with 3 months of calcitriol treatment. Dialysis vintage, body mass index (BMI), underlying etiologies of ESRD and prior calcitriol usage were not significantly differing between two groups. All patients had high serum iPTH levels [CCC, $1034 \pm 270 \mathrm{pg} / \mathrm{mL}$ vs. CCP, $1016 \pm 252 \mathrm{pg} / \mathrm{mL}$ ] and low 25(OH)D $\mathrm{D}_{3}$ levels [CCC, $18.2 \pm 8.4 \mathrm{ng} / \mathrm{mL}$ vs. CCP, $19.2 \pm 7.4 \mathrm{ng} / \mathrm{mL}$. Serum albumin, ALP, cCa and P levels were not significantly different. 
Table 1. Demographic characteristics and baseline data of the two groups under study.

\begin{tabular}{ccc}
\hline Characteristics & CCC $(\boldsymbol{n}=\mathbf{2 7})$ & CCP $(\boldsymbol{n}=\mathbf{2 8})$ \\
\hline Age, mean \pm SD (years) & $66.2 \pm 12.8$ & $65.6 \pm 13.4$ \\
Male, $n(\%)$ & $16(59 \%)$ & $14(50 \%)$ \\
BMI $\left(\mathrm{kg} / \mathrm{m}^{2}\right)$ & $21.94 \pm 3.48$ & $22.32 \pm 4.14$ \\
HD vintage (months) & $52.8 \pm 28.5$ & $54.5 \pm 29.6$ \\
GN, $n(\%)$ & $4(15 \%)$ & $6(21 \%)$ \\
DM, $n(\%)$ & $13(48 \%)$ & $12(43 \%)$ \\
HTN, $n(\%)$ & $5(19 \%)$ & $4(14 \%)$ \\
Others, $n(\%)$ & $5(19 \%)$ & $6(21 \%)$ \\
Prior calcitriol usage, $n(\%)$ & $25(93 \%)$ & $24(86 \%)$ \\
iPTH (pg/mL) & $1026 \pm 266$ & $1018 \pm 261$ \\
25(OH)D $(\mathrm{ng} / \mathrm{mL})$ & $18.2 \pm 8.4$ & $19.2 \pm 7.4$ \\
Albumin $(\mathrm{g} / \mathrm{dL})$ & $3.62 \pm 0.41$ & $3.64 \pm 0.38$ \\
Alkaline phosphatase $(\mathrm{U} / \mathrm{L})$ & $301.2 \pm 84.3$ & $292.8 \pm 92.4$ \\
cCa $(\mathrm{mg} / \mathrm{dL})$ & $10.4 \pm 0.61$ & $10.2 \pm 0.65$ \\
P $(\mathrm{mg} / \mathrm{dL})$ & $5.18 \pm 0.84$ & $5.24 \pm 0.76$ \\
\hline
\end{tabular}

Data are expressed as the mean $\pm \mathrm{SD}, n(\%)$, or median (interquartile range). SD: standard deviation; BMI, body mass index; HD, hemodialysis; GN, primary glomerulonephritis; DM, diabetes mellitus; HTN, hypertension; Others, vascular or ischemic nephropathy and tubulointerstitial nephritis; iPTH, parathyroid hormone; $25(\mathrm{OH}) \mathrm{D}_{3}, 25$-Hydroxyvitamin D; cCa, albumin-corrected calcium; P, phosphorus. CCC: Cinacalcet + Calcitriol + Cholecalciferol; CCP: Cinacalcet + Calcitriol + Placebo.

\subsection{Changes in Serum Intact Parathyroid Hormone (iPTH) Levels during the Study Period}

At 24 weeks, an average target iPTH level $(\leq 300 \mathrm{pg} / \mathrm{mL})$ was achieved in the CCC group but not in the CCP group (Table 2). The serum iPTH levels were significantly lower in the CCC group compared to the CCP group from the 20th week of the study, $336.4 \pm 124.1 \mathrm{pg} / \mathrm{mL}$ in the CCC group vs. $404.4 \pm 107.0 \mathrm{pg} / \mathrm{mL}$ in the CCP group $(p=0.034)$ at 20th week (Table 3 \& Figure 2). The median changes in iPTH levels from baseline were significantly different as early as the 16th week of the study, $-528.5 \pm 148.1 \mathrm{pg} / \mathrm{mL}$ in the CCC group vs. $-451.6 \pm 116.0 \mathrm{pg} / \mathrm{mL}$ in the CCP group $(p=0.036)$ (Table 3). In subgroup analysis of the patients with severe vitamin D deficiency (25(OH)D3 $<12.5 \mathrm{ng} / \mathrm{mL}$ ), serum iPTH levels were significantly different between the two groups at the 12th week, $486.5 \pm 203.9 \mathrm{pg} / \mathrm{mL}$ in the CCC group vs. $841.5 \pm 209.1 \mathrm{pg} / \mathrm{mL}$ in the CCP group $(p=0.024)$ (Table 4). The target iPTH level $(\leq 300 \mathrm{pg} / \mathrm{mL})$ was achieved from the 20th week in the CCC group compared with the CCP group in this subgroup of patients (Table 4). The mean dose of calcitriol use during the course of treatment was reduced progressively in the CCC group to control serum iPTH levels (Table 5). Dialysate calcium and doses of phosphate binder use did not differ significantly between the groups (data not shown). We further found that $11.1 \%, 29.6 \%, 55.6 \%$ and $81.5 \%$ of the study CCC group and $7.1 \%, 10.7 \%, 14.3 \%$ and $25 \%$ of the control CCP group achieved the target iPTH level at the 12th, 16th, 18th, 20th and 24th weeks, respectively (Table 6). Significantly more patients in the study group achieved the target level from the 20th week of the study (15/27 vs. $4 / 28, p=0.046$ at 20th wk; $22 / 27$ vs. $7 / 28, p=0.033$ at 24 th wk (chi-square test)) (Table 6 ). Most of our patients tolerated $30 \mathrm{mg}$ of cinacalcet and none of the patients had hypocalcemia $(\mathrm{cCa}<8.4 \mathrm{mg} / \mathrm{dL})$ during the study period. 


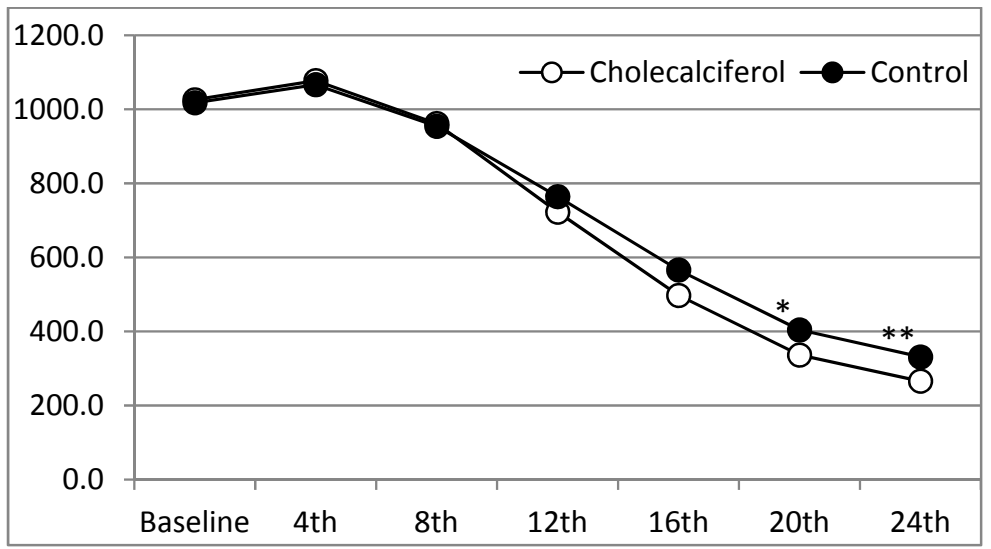

Figure 2. Changes in serum intact parathyroid hormone (iPTH) levels from baseline in two groups under study.

Table 2. Serum biochemistry parameters change among the two groups under study.

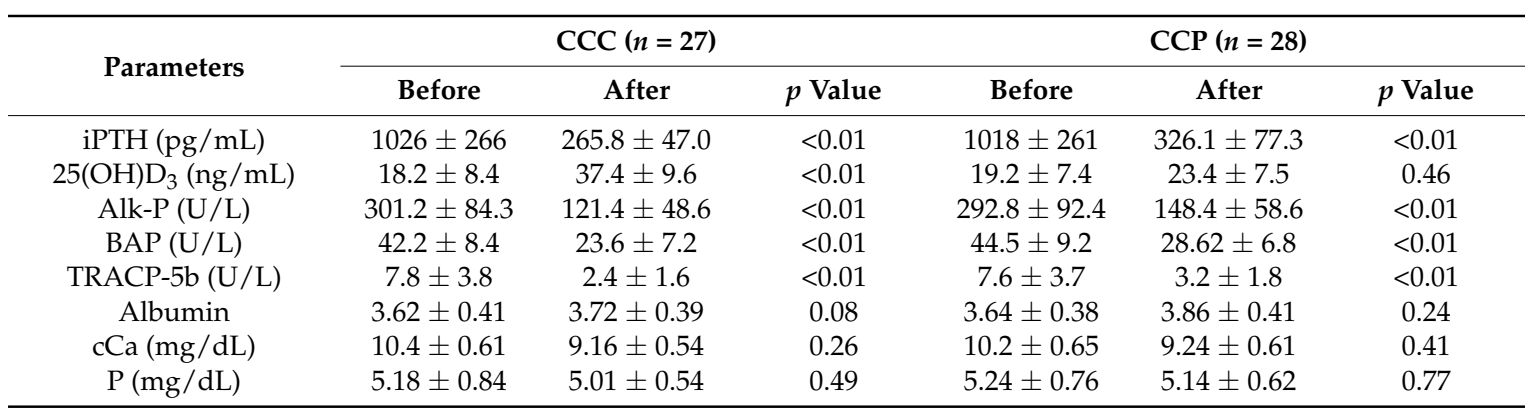

iPTH, parathyroid hormone; 25(OH)D3, 25-Hydroxyvitamin D; Alk-P, alkaline phosphatase; BAP, bone alkaline phosphatase; TRACP-5b, tartrate-resistant acid phosphatase $5 \mathrm{~b}$; $\mathrm{cCa}$, albumin-corrected calcium; $\mathrm{P}$, phosphorus.

Table 3. Serum iPTH levels and mean iPTH change from baseline in the two groups under study.

\begin{tabular}{|c|c|c|c|c|c|c|}
\hline Week & $\operatorname{CCC}(n=27)$ & $\mathrm{CCP}(n=28)$ & $p$ Value * & $\operatorname{CCC}(n=27)$ & $\mathrm{CCP}(n=28)$ & $p$ Value \\
\hline Baseline & $1026.1 \pm 266.1$ & $1018.0 \pm 260.5$ & 0.909 & - & - & - \\
\hline 8th week & $961.7 \pm 243.0$ & $954.4 \pm 236.6$ & 0.910 & $-64.2 \pm 39.7$ & $-63.2 \pm 39.7$ & 0.925 \\
\hline 12th week & $722.5 \pm 247.3$ & $764.5 \pm 191.0$ & 0.483 & $-303.5 \pm 151.2$ & $-253.2 \pm 75.9$ & 0.123 \\
\hline 16th week & $497.6 \pm 182.5$ & $566.1 \pm 153.7$ & 0.137 & $-528.5 \pm 148.1$ & $-451.6 \pm 116.0$ & 0.036 \\
\hline 24th week & $265.8 \pm 47.0$ & $326.1 \pm 77.3$ & 0.001 & $-760.3 \pm 257.3$ & $-686.8 \pm 212.0$ & 0.252 \\
\hline
\end{tabular}

Table 4. Serum iPTH levels changes in patients with baseline $25(\mathrm{OH}) \mathrm{D} 3<12.5 \mathrm{ng} / \mathrm{mL}$.

\begin{tabular}{cccc}
\hline Week & CCC $(\boldsymbol{n}=\mathbf{6})$ & CCP $(\boldsymbol{n}=\mathbf{5})$ & $\boldsymbol{p}$ Value \\
\hline Baseline & $1034.6 \pm 282.4$ & $1124.2 \pm 284.6$ & 0.612 \\
4th week & $1038.4 \pm 284.8$ & $1106.7 \pm 274.2$ & 0.697 \\
8th week & $864.3 \pm 262.1$ & $965.4 \pm 266.4$ & 0.543 \\
12th week & $486.5 \pm 203.9$ & $841.5 \pm 209.1$ & 0.024 \\
16th week & $354.2 \pm 153.5$ & $642.2 \pm 193.7$ & 0.022 \\
20th week & $265.7 \pm 108.3$ & $482.3 \pm 168.8$ & 0.029 \\
24th week & $225.5 \pm 34.1$ & $384.6 \pm 136.4$ & 0.021 \\
\hline
\end{tabular}


Table 5. Mean dose of intravenous calcitriol ( $\mu \mathrm{g} /$ week) during the course of treatment.

\begin{tabular}{ccc}
\hline Week & CCC $(\boldsymbol{n}=\mathbf{2 7})$ & CCP $(\boldsymbol{n}=\mathbf{2 8})$ \\
\hline Baseline & $3 \mu \mathrm{g} /$ week & $3 \mu \mathrm{g} /$ week \\
4th week & $3 \mu \mathrm{g} /$ week & $3 \mu \mathrm{g} /$ week \\
8th week & $3 \mu \mathrm{g} /$ week & $3 \mu \mathrm{g} /$ week \\
12th week & $2.67 \mu \mathrm{g} /$ week & $3 \mu \mathrm{g} /$ week \\
16th week & $2.22 \mu \mathrm{g} /$ week & $2.79 \mu \mathrm{g} /$ week \\
20th week & $1.44 \mu \mathrm{g} /$ week & $2.57 \mu \mathrm{g} /$ week \\
24th week & $0.56 \mu \mathrm{g} /$ week & $2.25 \mu \mathrm{g} /$ week \\
\hline
\end{tabular}

Table 6. Number of study patients achieving primary and secondary outcomes in the two groups under study.

\begin{tabular}{|c|c|c|c|c|}
\hline Primary Outcome & 12th Week & 16th Week & 20th Week & 24th Week \\
\hline $\begin{array}{c}\mathrm{iPTH} \leq 300 \mathrm{pg} / \mathrm{mL} \\
\mathrm{CCC}(n=27) \\
\text { CCP }(n=28)\end{array}$ & $\begin{array}{c}3 / 27(11.1 \%) \\
2 / 28(7.1 \%) \\
p=1.000\end{array}$ & $\begin{array}{c}8 / 27(29.6 \%) \\
3 / 28(10.7 \%) \\
p=0.270\end{array}$ & $\begin{array}{c}15 / 27(55.6 \%) \\
4 / 28(14.3 \%) \\
p=0.046\end{array}$ & $\begin{array}{c}22 / 27(81.5 \%) \\
7 / 28(25 \%) \\
p=0.033\end{array}$ \\
\hline Secondary Outcome & 12th Week & 16th Week & 20th Week & 24th Week \\
\hline $\begin{array}{c}25(\mathrm{OH}) \mathrm{D}_{3} \geq 30 \mathrm{ng} / \mathrm{dL} \\
\mathrm{CCC}(n=27) \\
\mathrm{CCP}(n=28)\end{array}$ & $\begin{array}{c}21 / 27(77.8 \%) \\
2 / 28(7.1 \%) \\
p=0.001\end{array}$ & & & $\begin{array}{c}24 / 27(88.9 \%) \\
3 / 28(10.7 \%) \\
p=0.001\end{array}$ \\
\hline$\uparrow$ FN-BMD > 10\% & & & & \\
\hline $\begin{array}{l}\mathrm{CCC}(n=27) \\
\operatorname{CCP~}(n=28)\end{array}$ & & & & $\begin{array}{c}13 / 27(40 \%) \\
5 / 28(6.7 \%) \\
p=0.150\end{array}$ \\
\hline
\end{tabular}

\subsection{Changes in Serum 25(OH)D3 Levels during the Study Period}

In the CCC group, $25(\mathrm{OH}) \mathrm{D}_{3}$ levels increased significantly from $18.2 \pm 8.4$ to $37.4 \pm 9.6(p<0.01)$ at the end of the study. However, in the $\mathrm{CCP}$ group, $25(\mathrm{OH}) \mathrm{D}_{3}$ levels did not change significantly (from $19.2 \pm 7.4$ to $23.4 \pm 7.5(p=0.46)$ ) (Table 2). A significant number of patients in the CCC group achieved target $25(\mathrm{OH}) \mathrm{D}_{3}$ level $(\geq 30 \mathrm{ng} / \mathrm{dL})$ as early as the 12 th week compared to the CCP group $(21 / 27(78 \%)$ vs. $2 / 28(7 \%), p=0.001$ at 12 th week); and nearly $89 \%$ of the CCC group vs only $10.7 \%$ in the CCP group achieved the target level at the end of the study $(24 / 27$ vs. $3 / 28, p=0.001$ (chi-square test)) (Table 6).

\subsection{Changes in Serum Bone Turnover Markers and Bone Mineral Densities}

Serum BAP and TRACP-5b levels were not significantly different between the groups (Table 2). No obvious changes in serum Alk-P, cCa and P were noted. Although no significant differences in femoral neck and lumbar spine BMD were noted between the two groups (Table 7), the number of patients who had 10\% increase in FN BMD was insignificantly higher in the CCC group ((13/27) 40\%) compared with the CCP group ((5/28) 6.7\%) (Table 6).

Table 7. Bone mineral density (BMD) changes after 24 weeks of treatment in the two groups under study.

\begin{tabular}{ccccccc}
\hline \multirow{2}{*}{ Parameters } & \multicolumn{3}{c}{ CCC $(\boldsymbol{n}=\mathbf{2 7})$} & \multicolumn{3}{c}{ CCP $(\boldsymbol{n}=\mathbf{2 8})$} \\
\cline { 2 - 7 } & Before & After & $\boldsymbol{p}$ Value & Before & After & $\boldsymbol{p}$ Value \\
\hline FN-BMD $\left(\mathrm{g} / \mathrm{cm}^{2}\right)$ & $0.57 \pm 0.04$ & $0.67 \pm 0.07$ & $<0.05$ & $0.58 \pm 0.05$ & $0.62 \pm 0.06$ & $<0.05$ \\
FN-T score & $-2.1 \pm 0.5$ & $-1.2 \pm 0.4$ & $<0.05$ & $-2.2 \pm 0.6$ & $-1.8 \pm 0.5$ & $<0.05$ \\
LS-BMD $\left(\mathrm{g} / \mathrm{cm}^{2}\right)$ & $0.91 \pm 0.09$ & $0.96 \pm 0.10$ & $<0.05$ & $0.89 \pm 0.07$ & $0.94 \pm 0.08$ & $<0.05$ \\
LS-T score & $-0.7 \pm 0.8$ & $-0.6 \pm 0.7$ & 0.627 & $-0.8 \pm 0.7$ & $-0.7 \pm 0.6$ & 0.568 \\
\hline
\end{tabular}

Data are expressed as mean \pm standard error. 


\section{Discussion}

Our results demonstrated that more than $80 \%$ of patients with severe SHPT achieved the primary target serum iPTH $\leq 300 \mathrm{pg} / \mathrm{ml}$ level with cholecalciferol supplementation. Nearly $90 \%$ of patients achieved the target serum $25-(\mathrm{OH}) \mathrm{D}_{3}(\geq 30 \mathrm{ng} / \mathrm{mL})$ with high-dose cholecalciferol supplementation (5000 IU/day). About 40\% of patients receiving cholecalciferol achieved a 10\% increase in FN BMD by the end of the study. To our knowledge, this is the first study to reveal the beneficial effects of cholecalciferol supplementation in further lowering $\mathrm{PPTH}$ and bone density improvement when combined with cinacalcet and calcitriol among severe SHPT patients.

As previously described, cinacalcet significantly increases the oxyphil cells (OC) and chief cells (CC) OC/CC ratio (approx. increase 3.42 times) [24], further increases local calcitriol production [26], and regulates local PTH secretion in a paracrine/autocrine manner. Thus, the need for local $25(\mathrm{OH}) \mathrm{D}_{3}$ substrate increases with cinacalcet treatment. We proved in our study that addition of nutritional vitamin $\mathrm{D}$ (cholecalciferol) improves the $25(\mathrm{OH}) \mathrm{D}_{3}$ requirement by cinacalcet treatment, and further inhibits PTH secretion among those patients with severe SHPT when used in combination with cinacalcet/active vitamin D analogs. About $55 \%$ of the patients achieved the iPTH target $(\mathrm{iPTH} \leq 300 \mathrm{pg} / \mathrm{mL})$ at the 20th week and almost $81 \%$ of patients achieved that target after the 24 th week of cholecalciferol supplementation. This effect was also seen among those patients with severely deficient vitamin D levels (serum $25(\mathrm{OH}) \mathrm{D}_{3}<12.5 \mathrm{ng} / \mathrm{mL}$ ). Furthermore, a higher percentage of patients achieved the primary endpoint in the CCC group, irrespective of the prior use of active vitamin D, calcitriol.

Although the CCP group also significantly improved iPTH levels, the target iPTH level was not achieved in most patients by the end of the study. Previous studies also proved that cinacalcet therapy improved the targets of bone metabolism (PTH, Ca, P, and the Ca-P product (Ca-P)) when used alone [32] or in combination of low-dose active vitamin D analogs [7]. However, all these studies used titrated doses of cinacalcet (30-180 mg per day) according to biochemical measures. We used a single daily dose of cinacalcet ( $30 \mathrm{mg}$ per day) throughout our study, since the drug is not covered by health insurance in Taiwan and patients took the drug by self-payment. We also found that lower doses of calcitriol were needed among our study group with time (Table 5). Most of the CCC group patients achieved KDOQI targets [33] (serum PTH 150-300 pg/mL, Ca 8.4-9.5 mg/dL, P 3.5-5.5 mg/dL, CaxP product $<55 \mathrm{mg}^{2} / \mathrm{dL}^{2}$ ) and none had hypocalcemia. Since hypocalcemia is the major event prohibiting the use of cinacalcet, and hypercalcemia is a major complication of active vitamin D analogs, the supplementation of nutritional vitamin D avoids both hypo- and hypercalcemic events in such combination therapy.

We found that up to $70 \%$ of CCC patients achieved the target $25(\mathrm{OH}) \mathrm{D}_{3}$ level $(\geq 30 \mathrm{ng} / \mathrm{mL})$ from the 12 th week of supplementation and nearly $90 \%$ had the target level by the end of the study. However, no such improvement was seen in the CCP group. Clinical studies reported that the combined use of nutritional vitamin D might reduce the active vitamin D doses [3,34] and improve adverse effects. Accordingly, we found our CCC group patients used progressively lower doses of calcitriol compared to the CCP group. Studies regarding the effective dosage of vitamin D supplementation are still controversial $[35,36]$. Our previous study used low-dose cholecalciferol (5000 IU/week) and about $60 \%$ of patients achieved the target $25(\mathrm{OH}) \mathrm{D}_{3}$ level $(\geq 30 \mathrm{ng} / \mathrm{dL})$ at 16 weeks [10]. Growing evidence shows that active vitamin $\mathrm{D}$ analogs may aggravate $25(\mathrm{OH}) \mathrm{D}_{3}$ deficiency because of the feedback inhibition of hepatic $1 \alpha$-OHase and $25 \alpha$-OHase [37,38] and induction of the 24-OHase enzyme [39]. Thus, we used quite a high dose of cholecalciferol (5000 IU/day) in combination with calcitriol in our study. We closely monitored $25(\mathrm{OH}) \mathrm{D}_{3}$ levels to avoid toxicity, and all of our patients tolerate high-dose cholecalciferol supplementation (5000 IU/day) well.

The next major observation of our study was that about $40 \%$ in the CCC group gained $>10 \%$ improvement in femoral BMD compared with the CCP group ( $7 \%)$. Other clinical studies also revealed that calcimimetic agents reduced the elevated bone formation rate/tissue area with improvement in high turnover bone disorders $[40,41]$. In a recent Indian study among CKD patients, researchers 
found a significant reduction in iPTH and bone turnover markers, bone-specific alkaline phosphatase (BAP) and serum C-terminal cross-linked collagen type I telopeptides (CTX-1) with cholecalciferol supplementation [42]. Previous studies [43,44] also proved that cinacalcet treatment improves the BMD of the FN without affecting the LS BMD. How and whether the combination of these agents interacts to improve bone parameters needs to be explored in future studies.

Our study has several limitations. Firstly, we cannot apply our findings or draw definitive conclusions in the general HD population due to the relatively small sample size; however, the results were indeed promising and clinically important. We used fixed low doses of cinacalcet in both study and control arms, which needed to be followed longer for efficiency. Furthermore, we excluded patients with severe malnutrition and inflammatory or infectious disorders who might have benefited the most from the intervention due to vitamin $\mathrm{D}$ deficiency. However, our cohort had significantly low vitamin D levels in both arms of the study. Next, we did not determine the morbidity or mortality benefits of combination therapy. Although we performed some questionnaires on various bone fractures, the results were inconsistent and non-significant due to shorter follow-up duration. The optimal serum $25(\mathrm{OH}) \mathrm{D}_{3}$ target level in dialysis patients remains unknown; however, we supposed some additive PTH lowering effects with $25(\mathrm{OH}) \mathrm{D}_{3} \geq 30 \mathrm{ng} / \mathrm{dL}$. Although no toxicity levels and signs were noted in our patients, the beneficial role and possible side effects of high-dose cholecalciferol in dialysis patients still requires a multifaceted long-term approach and needs further study in larger clinical trials.

\section{Conclusions}

Our findings provide in vivo evidence that $25(\mathrm{OH}) \mathrm{D}_{3}$ repletion with high-dose cholecalciferol acts additively with low-dose cinacalcet and active vitamin $\mathrm{D}$ analogs to gain $\mathrm{K} / \mathrm{DOQI}$ targets of bone metabolism markers and improve femoral neck bone mineral density in dialysis patients. We recommend that the addition of cholecalciferol is more favorable than the titration of cinacalcet and calcitriol doses among severe SHPT patients.

Acknowledgments: We acknowledge the commitment and dedication of the study investigators at Cardinal Tien Hospital, Fu Jen Catholic University and Shuang Ho Hospital, Taipei Medical University. The clinical trial was funded by CTH 105A-215, CTH-106A-2B01, 103TMU-SHH-28, CTH-100-1-2A0 and NC10003 for data collection, analysis, and preparation of the study report and manuscript.

Author Contributions: Kuo-Cheng Lu, Yuh-Feng Lin and Yung-Ho Hsu conceived and designed the trial; Chia-Chao Wu, Chi-Feng Hung, Min-Tser Liao and Jia-Fwu Shyu performed the trial; Chien-Lin Lu, Yuan-Hung Wang and Tian-Jong Chang analyzed the data; Cai-Mei Zheng wrote the paper. All authors read and approved the final manuscript.

Conflicts of Interest: The authors declare no conflict of interests.

\section{References}

1. Foley, R.N.; Parfrey, P.S.; Sarnak, M.J. Clinical epidemiology of cardiovascular disease in chronic renal disease. Am. J. Kidney Dis. Off. J. Natl. Kidney Found. 1998, 32, S112-S119. [CrossRef]

2. Massry, S.G.; Smogorzewski, M. Mechanisms through which parathyroid hormone mediates its deleterious effects on organ function in uremia. Semin. Nephrol. 1994, 14, 219-231. [PubMed]

3. Briese, S.; Wiesner, S.; Will, J.C.; Lembcke, A.; Opgen-Rhein, B.; Nissel, R.; Wernecke, K.D.; Andreae, J.; Haffner, D.; Querfeld, U. Arterial and cardiac disease in young adults with childhood-onset end-stage renal disease-impact of calcium and vitamin D therapy. Nephrol. Dial. Transplant. Off. Publ. Eur. Dial. Transpl. Assoc. Eur. Ren. Assoc. 2006, 21, 1906-1914. [CrossRef] [PubMed]

4. Lomashvili, K.A.; Wang, X.; O'Neill, W.C. Role of local versus systemic vitamin D receptors in vascular calcification. Arterioscler. Thromb. Vasc. Biol. 2014, 34, 146-151. [CrossRef] [PubMed]

5. Chertow, G.M.; Blumenthal, S.; Turner, S.; Roppolo, M.; Stern, L.; Chi, E.M.; Reed, J.; Investigators, C. Cinacalcet hydrochloride (sensipar) in hemodialysis patients on active vitamin D derivatives with controlled PTH and elevated calcium x phosphate. Clin. J. Am. Soc. Nephrol. CJASN 2006, 1, 305-312. [CrossRef] [PubMed] 
6. Block, G.A.; Zeig, S.; Sugihara, J.; Chertow, G.M.; Chi, E.M.; Turner, S.A.; Bushinsky, D.A.; Investigators, T. Combined therapy with cinacalcet and low doses of vitamin D sterols in patients with moderate to severe secondary hyperparathyroidism. Nephrol. Dial. Transplant. Off. Publ. Eur. Dial. Transpl. Assoc. Eur. Ren. Assoc. 2008, 23, 2311-2318. [CrossRef] [PubMed]

7. Fishbane, S.; Shapiro, W.B.; Corry, D.B.; Vicks, S.L.; Roppolo, M.; Rappaport, K.; Ling, X.; Goodman, W.G.; Turner, S.; Charytan, C. Cinacalcet hcl and concurrent low-dose vitamin D improves treatment of secondary hyperparathyroidism in dialysis patients compared with vitamin $\mathrm{D}$ alone: The achieve study results. Clin. J. Am. Soc. Nephrol. CJASN 2008, 3, 1718-1725. [CrossRef] [PubMed]

8. Messa, P.; Macario, F.; Yaqoob, M.; Bouman, K.; Braun, J.; von Albertini, B.; Brink, H.; Maduell, F.; Graf, H.; Frazao, J.M.; et al. The optima study: Assessing a new cinacalcet (sensipar/mimpara) treatment algorithm for secondary hyperparathyroidism. Clin. J. Am. Soc. Nephrol. CJASN 2008, 3, 36-45. [CrossRef] [PubMed]

9. Block, G.A.; Martin, K.J.; de Francisco, A.L.; Turner, S.A.; Avram, M.M.; Suranyi, M.G.; Hercz, G.; Cunningham, J.; Abu-Alfa, A.K.; Messa, P.; et al. Cinacalcet for secondary hyperparathyroidism in patients receiving hemodialysis. N. Engl. J. Med. 2004, 350, 1516-1525. [CrossRef] [PubMed]

10. Zheng, J.Q.; Hou, Y.C.; Zheng, C.M.; Lu, C.L.; Liu, W.C.; Wu, C.C.; Huang, M.T.; Lin, Y.F.; Lu, K.C. Cholecalciferol additively reduces serum parathyroid hormone and increases vitamin $\mathrm{D}$ and cathelicidin levels in paricalcitol-treated secondary hyperparathyroid hemodialysis patients. Nutrients 2016, 8, 708. [CrossRef] [PubMed]

11. Harkness, L.; Cromer, B. Low levels of 25-hydroxy vitamin D are associated with elevated parathyroid hormone in healthy adolescent females. Osteoporos. Int. 2005, 16, 109-113. [CrossRef] [PubMed]

12. Vieth, R.; Ladak, Y.; Walfish, P.G. Age-related changes in the 25-hydroxyvitamin D versus parathyroid hormone relationship suggest a different reason why older adults require more vitamin D. J. Clin. Endocrinol. Metab. 2003, 88, 185-191. [CrossRef] [PubMed]

13. Dusso, A.; Brown, A.; Slatopolsky, E. Extrarenal production of calcitriol. Semin. Nephrol. 1994, 14, $144-155$. [PubMed]

14. Zehnder, D.; Bland, R.; Williams, M.C.; McNinch, R.W.; Howie, A.J.; Stewart, P.M.; Hewison, M. Extrarenal expression of 25-hydroxyvitamin d(3)-1 alpha-hydroxylase. J. Clin. Endocrinol. Metab. 2001, 86, 888-894. [PubMed]

15. Levin, A.; Bakris, G.L.; Molitch, M.; Smulders, M.; Tian, J.; Williams, L.A.; Andress, D.L. Prevalence of abnormal serum vitamin D, PTH, calcium, and phosphorus in patients with chronic kidney disease: Results of the study to evaluate early kidney disease. Kidney Int. 2007, 71, 31-38. [CrossRef] [PubMed]

16. Cho, H.Y.; Hyun, H.S.; Kang, H.G.; Ha, I.S.; Cheong, H.I. Prevalence of 25(oh) vitamin D insufficiency and deficiency in pediatric patients on chronic dialysis. Perit. Dial. Int. 2013, 33, 398-404. [CrossRef] [PubMed]

17. Segersten, U.; Correa, P.; Hewison, M.; Hellman, P.; Dralle, H.; Carling, T.; Akerstrom, G.; Westin, G. 25-hydroxyvitamin d(3)-1alpha-hydroxylase expression in normal and pathological parathyroid glands. J. Clin. Endocrinol. Metab. 2002, 87, 2967-2972. [PubMed]

18. Correa, P.; Segersten, U.; Hellman, P.; Akerstrom, G.; Westin, G. Increased 25-hydroxyvitamin d3 1alpha-hydroxylase and reduced 25-hydroxyvitamin d3 24-hydroxylase expression in parathyroid tumors-New prospects for treatment of hyperparathyroidism with vitamin D. J. Clin. Endocrinol. Metab. 2002, 87, 5826-5829. [CrossRef] [PubMed]

19. Ritter, C.S.; Armbrecht, H.J.; Slatopolsky, E.; Brown, A.J. 25-hydroxyvitamin d(3) suppresses PTH synthesis and secretion by bovine parathyroid cells. Kidney Int. 2006, 70, 654-659. [CrossRef] [PubMed]

20. Christie, A.C. The parathyroid oxyphil cells. J. Clin. Pathol. 1967, 20, 591-602. [CrossRef] [PubMed]

21. Lomonte, C.; Martino, R.; Selvaggiolo, M.; Bona, R.M.; Cazzato, F.; Milano, R.; Chiarulli, G.; Basile, C. Calcitriol pulse therapy and histology of parathyroid glands in hemodialysis patients. J. Nephrol. 2003, 16, 716-720. [PubMed]

22. Mizobuchi, M.; Ogata, H.; Hatamura, I.; Saji, F.; Koiwa, F.; Kinugasa, E.; Koshikawa, S.; Akizawa, T. Activation of calcium-sensing receptor accelerates apoptosis in hyperplastic parathyroid cells. Biochem. Biophys. Res. Commun. 2007, 362, 11-16. [CrossRef] [PubMed]

23. Drueke, T.; Martin, D.; Rodriguez, M. Can calcimimetics inhibit parathyroid hyperplasia? Evidence from preclinical studies. Nephrol. Dial. Transplant. Off. Publ. Eur. Dial. Transpl. Assoc. Eur. Ren. Assoc. 2007, 22, 1828-1839. [CrossRef] [PubMed] 
24. Lomonte, C.; Vernaglione, L.; Chimienti, D.; Bruno, A.; Cocola, S.; Teutonico, A.; Cazzato, F.; Basile, C. Does vitamin $\mathrm{D}$ receptor and calcium receptor activation therapy play a role in the histopathologic alterations of parathyroid glands in refractory uremic hyperparathyroidism? Clin. J. Am. Soc. Nephrol. CJASN 2008, 3, 794-799. [CrossRef] [PubMed]

25. Sumida, K.; Nakamura, M.; Ubara, Y.; Marui, Y.; Tanaka, K.; Takaichi, K.; Tomikawa, S.; Inoshita, N.; Ohashi, K. Histopathological alterations of the parathyroid glands in haemodialysis patients with secondary hyperparathyroidism refractory to cinacalcet hydrochloride. J. Clin. Pathol. 2011, 64, 756-760. [CrossRef] [PubMed]

26. Ritter, C.S.; Haughey, B.H.; Armbrecht, H.J.; Brown, A.J. Distribution and regulation of the 25-hydroxyvitamin d3 1alpha-hydroxylase in human parathyroid glands. J. Steroid Biochem. Mol. Biol. 2012, 130, 73-80. [CrossRef] [PubMed]

27. Mendoza, F.J.; Lopez, I.; Canalejo, R.; Almaden, Y.; Martin, D.; Aguilera-Tejero, E.; Rodriguez, M. Direct upregulation of parathyroid calcium-sensing receptor and vitamin $\mathrm{D}$ receptor by calcimimetics in uremic rats. Am. J. Physiol. Ren. Physiol. 2009, 296, F605-F613. [CrossRef] [PubMed]

28. Mizobuchi, M.; Hatamura, I.; Ogata, H.; Saji, F.; Uda, S.; Shiizaki, K.; Sakaguchi, T.; Negi, S.; Kinugasa, E.; Koshikawa, S.; et al. Calcimimetic compound upregulates decreased calcium-sensing receptor expression level in parathyroid glands of rats with chronic renal insufficiency. J. Am. Soc. Nephrol. 2004, 15, 2579-2587. [CrossRef] [PubMed]

29. Faul, F.; Erdfelder, E.; Lang, A.G.; Buchner, A. G* power 3: A flexible statistical power analysis program for the social, behavioral, and biomedical sciences. Behav. Res. Methods 2007, 39, 175-191. [CrossRef] [PubMed]

30. Barreto, F.C.; Barreto, D.V.; Moyses, R.M.; Neves, K.R.; Canziani, M.E.; Draibe, S.A.; Jorgetti, V.; Carvalho, A.B. $\mathrm{K} / \mathrm{DOQI}$-recommended intact PTH levels do not prevent low-turnover bone disease in hemodialysis patients. Kidney Int. 2008, 73, 771-777. [CrossRef] [PubMed]

31. Kovacevic, B.; Ignjatovic, M.; Zivaljevic, V.; Cuk, V.; Scepanovic, M.; Petrovic, Z.; Paunovic, I. Parathyroidectomy for the attainment of NKF-K/DOQI and kdigo recommended values for bone and mineral metabolism in dialysis patients with uncontrollable secondary hyperparathyroidism. Langenbecks Arch. Surg. 2012, 397, 413-420. [CrossRef] [PubMed]

32. Moe, S.M.; Chertow, G.M.; Coburn, J.W.; Quarles, L.D.; Goodman, W.G.; Block, G.A.; Drueke, T.B.; Cunningham, J.; Sherrard, D.J.; McCary, L.C.; et al. Achieving nkf-K/DOQI bone metabolism and disease treatment goals with cinacalcet hcl. Kidney Int. 2005, 67, 760-771. [CrossRef] [PubMed]

33. Noordzij, M.; Korevaar, J.C.; Boeschoten, E.W.; Dekker, F.W.; Bos, W.J.; Krediet, R.T. Netherlands Cooperative Study on the Adequacy of Dialysis Study, G. The kidney disease outcomes quality initiative (K/DOQI) guideline for bone metabolism and disease in ckd: Association with mortality in dialysis patients. Am. J. Kidney Dis. Off. J. Natl. Kidney Found. 2005, 46, 925-932. [CrossRef] [PubMed]

34. Liu, W.C.; Wu, C.C.; Hung, Y.M.; Liao, M.T.; Shyu, J.F.; Lin, Y.F.; Lu, K.C.; Yeh, K.C. Pleiotropic effects of vitamin D in chronic kidney disease. Clin. Chim. Acta 2016, 453, 1-12. [CrossRef] [PubMed]

35. Delanaye, P.; Weekers, L.; Warling, X.; Moonen, M.; Smelten, N.; Medart, L.; Krzesinski, J.M.; Cavalier, E. Cholecalciferol in haemodialysis patients: A randomized, double-blind, proof-of-concept and safety study. Nephrol. Dial. Transplant. Off. Publ. Eur. Dial. Transpl. Assoc. Eur. Ren. Assoc. 2013, 28, 1779-1786. [CrossRef] [PubMed]

36. Bansal, B.; Bansal, S.B.; Mithal, A.; Kher, V.; Marwaha, R.; Singh, P.; Irfan, N. A randomized controlled trial of cholecalciferol supplementation in patients on maintenance hemodialysis. Indian J. Endocrinol. Metab. 2014, 18, 655-661. [PubMed]

37. Ding, C.; Gao, D.; Wilding, J.; Trayhurn, P.; Bing, C. Vitamin D signalling in adipose tissue. Br. J. Nutr. 2012, 108, 1915-1923. [CrossRef] [PubMed]

38. Bell, N.H.; Shaw, S.; Turner, R.T. Evidence that 1,25-dihydroxyvitamin D3 inhibits the hepatic production of 25-hydroxyvitamin D in man. J. Clin. Investig. 1984, 74, 1540-1544. [CrossRef] [PubMed]

39. Pike, J.W.; Meyer, M.B. Regulation of mouse Cyp24a1 expression via promoter-proximal and downstream-distal enhancers highlights new concepts of 1,25-dihydroxyvitamin D(3) action. Arch Biochem. Biophys. 2012, 523, 2-8. [CrossRef] [PubMed] 
40. Malluche, H.H.; Monier-Faugere, M.C.; Wang, G.; Fraza, O.J.; Charytan, C.; Coburn, J.W.; Coyne, D.W.; Kaplan, M.R.; Baker, N.; McCary, L.C.; et al. An assessment of cinacalcet HCL effects on bone histology in dialysis patients with secondary hyperparathyroidism. Clin. Nephrol. 2008, 69, 269-278. [CrossRef] [PubMed]

41. Behets, G.J.; Spasovski, G.; Sterling, L.R.; Goodman, W.G.; Spiegel, D.M.; De Broe, M.E.; D’Haese, P.C. Bone histomorphometry before and after long-term treatment with cinacalcet in dialysis patients with secondary hyperparathyroidism. Kidney Int. 2015, 87, 846-856. [CrossRef] [PubMed]

42. Yadav, A.K.; Kumar, V.; Kumar, V.; Banerjee, D.; Gupta, K.L.; Jha, V. The effect of vitamin D supplementation on bone metabolic markers in chronic kidney disease. J. Bone Miner. Res. Off. J. Am. Soc. Bone Miner. Res. 2017. [CrossRef] [PubMed]

43. Tsuruta, Y.; Okano, K.; Kikuchi, K.; Tsuruta, Y.; Akiba, T.; Nitta, K. Effects of cinacalcet on bone mineral density and bone markers in hemodialysis patients with secondary hyperparathyroidism. Clin. Exp. Nephrol. 2013, 17, 120-126. [CrossRef] [PubMed]

44. Lien, Y.H.; Silva, A.L.; Whittman, D. Effects of cinacalcet on bone mineral density in patients with secondary hyperparathyroidism. Nephrol. Dial. Transplant. Off. Publ. Eur. Dial. Transpl. Assoc. Eur. Ren. Assoc. 2005, 20, 1232-1237. [CrossRef] [PubMed]

(C) 2018 by the authors. Licensee MDPI, Basel, Switzerland. This article is an open access article distributed under the terms and conditions of the Creative Commons Attribution (CC BY) license (http://creativecommons.org/licenses/by/4.0/). 